\title{
Message of the President of the Brazilian League of Epilepsy
}

$\mathrm{O}$ s preparativos para o XXXII Congresso da Liga Brasileira de Epilepsia estão a todo vapor. A infra-estrutura do evento será de primeira qualidade e o programa científico atenderá as expectativas dos pesquisadores e clínicos em fase de formação e também os profissionais em busca atualização nos diversos aspectos relacionados ao diagnóstico e atendimento de pessoas com epilepsia. O número de inscrições e trabalhos submetidos está aumentando a cada dia. Nossa previsão é de 600 a 1000 congressistas para este evento.

O XXXII Congresso da Liga Brasileira de Epilepsia dará ênfase especial para atualização médica sobre os aspectos clínicos, diagnóstico e tratamento das crises e síndromes epilépticas, bem como das co-morbidades psiquiátricas em epilepsia. Teremos também um encontro das Associações de Pacientes com Epilepsia, e atividades educativas para os pacientes e familiares.

O congresso contará ainda com um Simpósio Especial para discussão e elaboração de um documento com posição oficial da Liga Brasileira de Epilepsia sobre a questão de Produtos Genéricos de Drogas Antiepilépticas e distribuição destes medicamentos no SUS.

Aproveito a oportunidade para convidar todos os sócios da LBE para a Assembléia Geral que ocorrerá no Hotel The Royal Palm Plaza, Campinas, durante o XXXII Congresso Brasileiro de Epilepsia, no dia 14 de junho de 2008, às 18 horas, em primeira chamada ou às $18 \mathrm{~h} 30 \mathrm{~min}$, em segunda chamada, com a presença de qualquer quorum, e encerramento às $20 \mathrm{~h} 30 \mathrm{~min}$.

O programa do congresso está no site $<$ http://www.eventus.com.br/epilepsia/ $>$.

\author{
Fernando Cendes \\ Presidente da Liga Brasileira de Epilepsia \\ 2006-2008
}

